\title{
Life Cycle Analysis for Hibiscus Sabdariffa Powder Manufactured by Freeze Drying for Wastewater Application
}

\author{
Woo Chieh Zheng, Nurhazwani Ismail ${ }^{*}$, Christine Olga Boboi, Chua Bee Lin \\ School of Computer Science and Engineering, Taylor's University Lakeside Campus, 1 Jalan \\ Taylor's, 47500 Subang Jaya, Selangor, Malaysia.
}

\begin{abstract}
Synthetic coagulants currently used to treat dye wastewater in the water treatment industry has been found to produce large amounts of waste and is bad for the environment. The research then presents two different methods of preparing Hibiscus Sabdariffa as a natural coagulant which are direct method and freeze-drying method to possibly replace synthetic coagulant in treating dye wastewater. The two different methods of preparing natural coagulant Hibiscus Sabdariffa are compared in terms of protein retention and coagulation performance at removing dye from dye wastewater. This is to determine which method of preparation is better at preparing a Hibiscus Sabdariffa as a natural coagulant to be used in the water treatment industry. Three analysis are done to determine the optimum concentration of Hibiscus Sabdariffa powder and freeze-drying duration is based on (i) surface morphology, (ii) water solubility and (iii) water activity. Optimum concentration of Hibiscus Sabdariffa powder is 20wt\% and 24hour freeze-drying duration. Another analysis is done to compare protein retention of each methods of preparation using (iv) Fourier Transform Infrared (FTIR) spectroscopy testing. Protein in Hibiscus Sabdariffa prepared using freeze drying is completely retained based on Fourier Transform Infrared spectroscopy results. Supporting data of protein retention properties of freeze drying is proven by water activity in Hibiscus Sabdariffa powder is at 0.478 and below the 0.6 threshold value. Water activity of 0.478 means that there is not enough water content in Hibiscus Sabdariffa powder for microorganisms to grow and degrade the protein. Optimum coagulant dosage and $\mathrm{pH}$ value that Hibiscus Sabdariffa prepared using the two different methods best works in is determined based on two experiments called (v) effects of coagulant dosage on dye removal percentage and (vi) effect of $\mathrm{pH}$ value of preparation methods on colour removal percentage. Coagulation performance of both preparation methods are also determined using experiment (v) and (vi). Hibiscus Sabdariffa prepared using freeze drying has better coagulation performance with higher colour removal percentage at lower required coagulant dosage and higher dye removal percentage at varied $\mathrm{pH}$ values compared to direct method. As a result, freeze drying is better in terms of coagulation performance compared to direct method at preparing natural coagulant Hibiscus
\end{abstract}

\footnotetext{
*Corresponding author: Nurhazwani.ismail@taylors.edu.my
} 
Sabdariffa. Coagulation performance of natural and chemical coagulant is compared using (vii) jar test comparison between natural and chemical coagulant on colour removal. This is to determine if coagulation performance of natural coagulant is comparable to chemical coagulant. Coagulation performance of natural coagulant is only slightly lower than synthetic coagulant at colour removal percentage of $91.2 \%$ compared to $92.3 \%$. This makes the coagulation performance of natural coagulant comparable to synthetic coagulant allowing it to be an alternative to synthetic coagulant based on coagulation performance. Therefore, Life Cycle Analysis (LCA) will then be conducted to compare the better method of preparation of natural coagulant which is freeze-drying of natural coagulant Hibiscus Sabdariffa to chemical coagulant alum. Life Cycle Analysis done is to determine, evaluate and compare natural against chemical coagulant based on 3 sustainability aspects economic, environment and social aspects. This is to determine the feasibility of natural coagulant Hibiscus Sabdariffa in the water treatment industry on whether it is a possible alternative or replacement to the currently used synthetic coagulant alum. Based on Life Cycle Analysis natural coagulant is the better alternative compared to chemical coagulant based on impact towards the environment and health and well-being of society. However, the implementation of natural coagulant in the water treatment industry is still not feasible as production cost of natural coagulant is 126.86 times more expensive compared to chemical coagulant. As a result, currently Hibiscus Sabdariffa as a natural coagulant is not able to replace synthetic coagulant alum in the water treatment industry.

\section{INTRODUCTION}

Chemical coagulants carry out coagulation process as the overall charge of the chemical coagulant is positively charged whereas dye is negatively charged. Neutralization of negative dye charges using positively charged chemical coagulant where chemical coagulant sticks on the surface of dye. As dye and chemical coagulant stick with one another in a process called coagulation [1]. Dye and coagulant agglomerate becoming heavier and denser. Dye is then removed from wastewater via sedimentation. Chemical coagulants such as alum are the coagulants that is currently being widely used in the water treatment industry especially treating dye wastewater. However, the problem statement of this report is that chemical coagulants have been found to be bad for the environment. This is because chemical sludge produced post water treatment process is large in quantity and non-biodegradable [2]. Biodegradation is a process where bacteria or fungus breakdown organic matter and organic matters are compounds that contain carbon. Chemical sludge is an inorganic compound as it does not contain carbon making it non-biodegradable. Since chemical sludge is nonbiodegradable and toxic, chemical sludge is known to cause water pollution which is an environmental issue. Since chemical sludge is toxic, it also negatively affects the health of aquatic life. There is also an article suggesting the contribution of chemical coagulants contribute to social issues as in neurological diseases such as dementia and Alzheimer's disease [3] when ingested by humans.

In this case, natural methods of coagulation are preferable in theory as it produces biodegradable sludge. The biodegradable sludge will not stay in the environment forever or a long time as it can degrade. As a result, biodegradable sludge is better for the environment compared to chemical coagulant [3]. Furthermore, biodegradable sludge produced from usage of natural coagulant is safe to aquatic live and human health as it is non-toxic. Natural coagulants such as Hibiscus Sabdariffa is biodegradable as the compounds responsible for 
the coagulation properties of Hibiscus Sabdariffa are proteins [4]. Proteins are organic matter as it contains carbon. Which brings the option of using natural coagulant, the Hibiscus Sabdariffa is proposed as an alternative coagulant to the chemical coagulants such as alum and even possibly replace them. The Hibiscus Sabdariffa is commonly used in the food and pharmaceutical fields. However, it can also be used as a natural coagulant due to the high protein content in the seeds. This is because like the mechanism of synthetic coagulant at treating dye wastewater. Protein content in Hibiscus Sabdariffa is positively charged whereas dye is negatively charged. Coagulation then happens between protein and dye causing it to become heavier and denser. This is where dye is removed from wastewater via sedimentation [1].

There are two methods of preparing Hibiscus Sabdariffa as a natural coagulant which are direct method and freeze-drying method. Direct method is where Hibiscus Sabdariffa seed is grinded into powder form where the powder will then be used a natural coagulant by simply pouring the powder into wastewater. Freeze drying on the other hand is a method of preserving food used in the industry. Like the direct method, the freeze-drying method involves the use of Hibiscus Sabdariffa and is grinded into powder form. However, in freezedrying there is an additional step where the powder is frozen to dehydrate the powder effectively preserving the protein content in the Hibiscus Sabdariffa powder [5]. This is because water is required by microorganisms to decompose the protein content in the Hibiscus Sabdariffa. By dehydrating the powder reducing the water content in the powder, it effectively prevents or at least reduce the rate of decomposition of Hibiscus Sabdariffa powder. Furthermore, protein content in the Hibiscus Sabdariffa is responsible for the coagulation action required to remove dye from wastewater. As a result of freeze drying, the coagulation performance of Hibiscus Sabdariffa powder as natural coagulant is maintained for a longer time span and the powder has longer shelf-life compared to direct method. Tests such as surface morphology, water solubility, water activity and Fourier Transform Infrared (FTIR) spectroscopy are done to not only determine the optimum concentration and freezedrying duration of Hibiscus Sabdariffa powder. It also acts as supporting data to claims of protein retention properties that the freeze-drying method has on natural coagulant Hibiscus Sabdariffa. These four tests also support the claim that coagulation performance of freezedrying should be better than direct method.

However, to directly determine that freeze-drying method is better than direct method at preparing Hibiscus Sabdariffa as a natural coagulant. The coagulation performance of the two different methods of preparing Hibiscus Sabdariffa powder must be proven via results from experimentation. Experiment where effect of coagulant dosage on dye removal percentage and effect of $\mathrm{pH}$ value of preparation methods on colour removal percentage is done. These two experiments are done to determine which method of preparation is better and in theory freeze-drying is better due to supporting data from the four tests mentioned above. The better method of preparation of Hibiscus Sabdariffa as a natural coagulant after being proven via results and commerciality will be chosen to be compared with the chemical coagulant. First off, commerciality of natural coagulant Hibiscus Sabdariffa prepared from two different methods to prove its feasibility to be an alternative and possibly replace synthetic coagulant alum in the water treatment industry. This is done through logical reasoning where natural coagulant has the weakness of protein degradation over time [6]. The coagulation performance of natural coagulant drops over time as protein is responsible for coagulation action. This means that natural coagulant cannot be stockpiled for use in treating dye in water treatment industry. Furthermore, the production of natural coagulant obtained from growing of Hibiscus Sabdariffa plant is time consuming and affected by uncertainties such as weather changes, sunlight, and water. This makes Hibiscus Sabdariffa a rather inconsistent natural coagulant for use in the water treatment industry as it may not be able to satisfy the natural coagulant requirement in the water treatment industry. On the 
other hand, synthetic coagulant production is consistent as raw materials and production process can be done consistently. Synthetic coagulant can also be stocked piled as it does not degrade maintaining its coagulation performance. This explains the important of freezedrying as it helps improve the protein retention of natural coagulant Hibiscus Sabdariffa maintaining its coagulation performance. It also allows Hibiscus Sabdariffa prepared using freeze-drying to be stockpiled without worry of protein degradation and drop in coagulation performance. Freeze drying also allows natural coagulant to satisfy the natural coagulant requirement in the water treatment industry. This is due to freeze-drying method overcoming the weakness of natural coagulant requiring time to grow of at least 4 weeks and its growth is affected by uncertainties [7]. In theory freeze drying is better than direct method of preparing natural coagulant Hibiscus Sabdariffa for treating dye in the water treatment industry based on coagulation performance results and commerciality.

The best current method of preparing Hibiscus Sabdariffa as a natural coagulant is then compared to chemical coagulant to determine if natural coagulant Hibiscus Sabdariffa can be replace synthetic coagulant alum. Coagulation performance comparison is the most important as if Hibiscus Sabdariffa is not anywhere near as good as chemical coagulant. Hibiscus Sabdariffa cannot replace chemical coagulant in the industry. Coagulation performance of natural and synthetic coagulant is compared via jar test comparison between natural and chemical coagulant on colour removal. Life Cycle Analysis comparison is then done where both natural coagulant Hibiscus Sabdariffa powder will be compared to chemical coagulant alum in terms of the 3 sustainability aspects which are economic, environmental, and social aspects. All of which is to determine and evaluate the effects that the usage of natural coagulant and chemical coagulant in the wastewater treatment industry has on the 3 sustainability aspects [8]. The 3 sustainability aspects are used to create a basis where comparison between natural coagulant and chemical coagulant can be done fairly and objectively. The better option between the two type of coagulants determined via Life Cycle Analysis will be used in the water treatment industry as the option that is better in terms of economic, environment and social is obviously the better choice of coagulant. Therefore, the main purpose of the research is the Life Cycle Analysis as it helps determine whether natural coagulant Hibiscus Sabdariffa is a possible alternative to replace chemical coagulant alum in the wastewater industry. As determining whether natural coagulant Hibiscus Sabdariffa can replace chemical coagulant alum in the wastewater industry based on economic feasibility, commerciality as a product, the impact of its usage on the environment and well-being and safety of society is one of the main research objective and research gap to be narrowed down.

\section{METHODOLOGY}

Research flowchart of the experiments is as shown in Figure 1 below. The powder characteristics testing where changes in surface morphology, water activity and water solubility of Hibiscus Sabdariffa due to freeze drying method will be determined. This helps determine the optimum concentration and freeze-drying duration that the Hibiscus Sabdariffa works best with. The better method of preparing Hibiscus Sabdariffa seed would in theory be the freeze-drying method. The claim that freeze drying is a better preparation method compared to direct method will be determine using Fourier Transform Infrared spectroscopy where retention of functional group protein is preserved. This is because protein is responsible for the coagulation process and preserving as much protein as possible would mean maximum coagulation performance of the Hibiscus Sabdariffa powder. This method's validity will be proven by the powder characteristics testing where changes that the Hibiscus Sabdariffa undergoes due to freeze drying can be seen and quantified in surface morphology, water activity and water solubility tests. It also acts as data which can help reason and prove why the changes that the Hibiscus Sabdariffa powder undergoing freeze drying is beneficial 
for the coagulation performance. Jar test is done on effect of coagulant dosage and $\mathrm{pH}$ value of two different methods of preparing Hibiscus Sabdariffa. This is to determine optimum coagulant dosage, $\mathrm{pH}$ levels and coagulation performance of both methods of preparing Hibiscus Sabdariffa. Another jar test is done to compare the coagulation performance between freeze drying Hibiscus Sabdariffa seed as natural coagulant and chemical coagulant alum (aluminium sulphate). This helps determine if Hibiscus Sabdariffa as a natural coagulant is a possible alternative to replace chemical coagulant in the water treating industry especially treating dye wastewater.

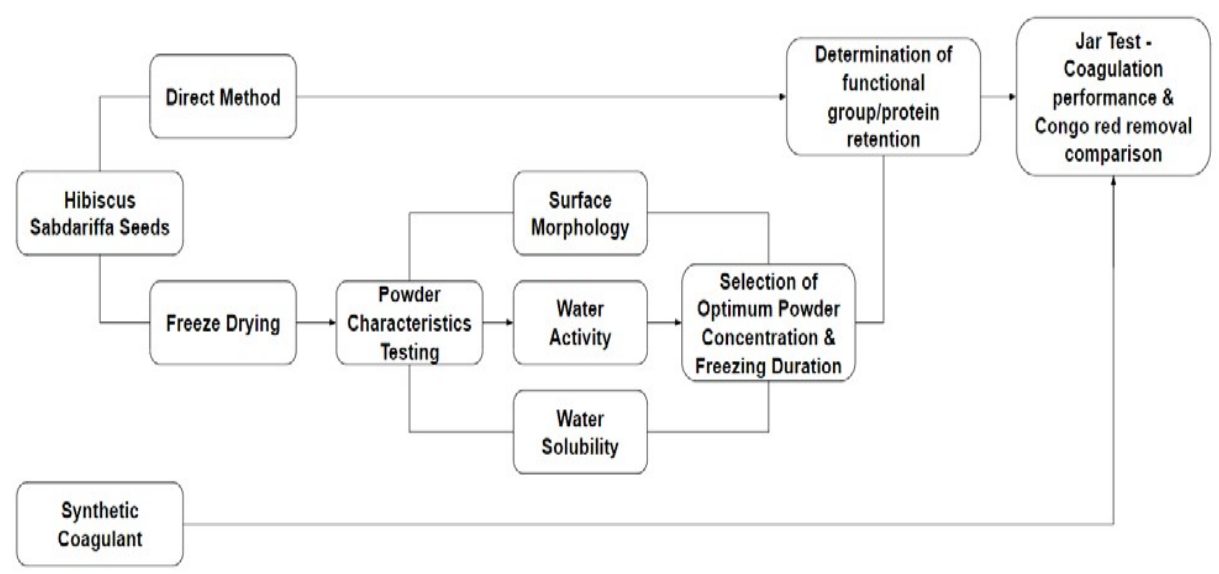

Fig. 1. Research flowchart of experiments

\section{LIFE CYCLE ANALYSIS}

Functional unit of Life Cycle Analysis is based on the amount of water required by a town with an average pollution of 25000 people [9]. Given that 1 person uses $201 \mathrm{~L}$ of water per day, the total water usage of the town can be calculated [10]. The amount of coagulant can then be calculated based on the amount of water used in the town at $1834125 \mathrm{~m}^{3}$ water/year with synthetic coagulant dosages of $36682.5 \mathrm{~kg} /$ year [11]. Since coagulation performance of natural coagulant is comparable to synthetic coagulant. Amount of synthetic coagulant used can be set as a basis of comparison for the Life Cycle Analysis where natural coagulant usage per year $36682.5 \mathrm{~kg} /$ year is also. This allows a fair comparison where both synthetic and natural coagulant dosages can be directly converted into cost of production where annual raw materials used and waste produced from the entire life cycle of synthetic coagulant and natural coagulant can be found and determined. Amount of sludge produced from both types of coagulant can then be found at $547500 \mathrm{~kg}$ dry sludge/year where synthetic coagulant produced toxic non-biodegradable sludge while and natural coagulant non-toxic biodegradable sludge [12].

System Boundary as shown in Figure 2, is where two different types of coagulation which is chemical coagulant and natural coagulant derived from freeze drying of Hibiscus Sabdariffa seed is used to treat dye wastewater. The system boundary is categorized under input, process, and output for ease of understanding. Life Cycle Analysis was conducted to compare freeze-drying of natural coagulant Hibiscus Sabdariffa to chemical coagulant alum. Life Cycle Analysis done is to determine and evaluate the natural and chemical coagulant based on 3 sustainability aspects economic, environment and social aspects with help of the system boundary above. The system boundary helps determine the steps that these coagulants 
undergo, the input and output material and waste are also considered. As a result, the Life Cycle Analysis is done based on all the aspects labelled above from sludge to wastes such as greenhouse gas emission to fertilizer waste.

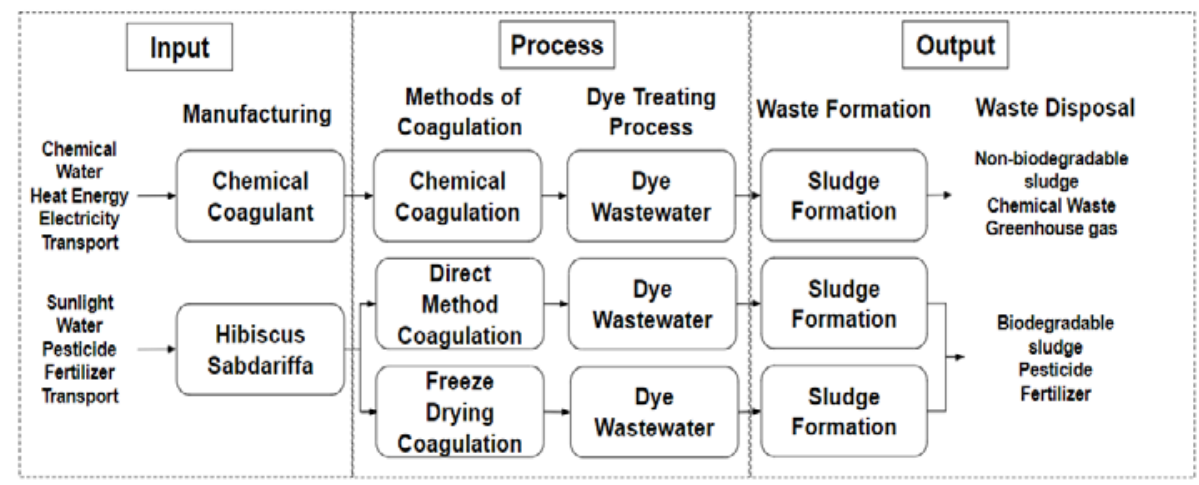

Fig. 2. System boundary of Hibiscus Sabdariffa seeds via different methods of coagulation

\section{RESULTS AND DISCUSSION}

Hibiscus Sabdariffa powder prepared from freeze drying is done based on the following steps. 0.5 gram of Hibiscus Sabdariffa seeds were mixed with $0.1 \mathrm{~L}$ of distilled water and blended to obtain powder concentration of $20 \mathrm{wt} \%$ and $30 \mathrm{wt} \%$. Mixture is then filtered with muslin cloth and the filtrate is collected. Maltodextrin of $7 \%(\mathrm{w} / \mathrm{v})$ and filtrate is mixed [13]. The filtrates are then pre-freeze in a freezer overnight at temperature of $-22^{\circ} \mathrm{C}$. Freeze drying of samples are then carried out at different freeze-drying durations of 24 and 65 hours [14]. The samples after the respective freeze-drying duration are then pounded using the traditional mortar and pestle. The samples are kept in Ziploc bags in airtight condition to make sure that moisture levels of samples are not changed after the freeze-drying process. Sample concentration and freeze-drying times are tabulated in Table 1 of water solubility test.

\subsection{Surface morphology}

Images in Figure 3 is obtained using scanning electron microscope (SEM). Based on Figure 3, all powders have non-uniform shape because it has been grinded using traditional pestle and mortar method using the powder obtained from the steps mentioned above [15]. All the powder is seen to have very porous surfaces. The porosity of the structure is due to the implementation of freeze-drying process where cavities are formed, these cavities form due to formation of ice crystals from the freeze-drying process. The freeze-drying process also dehydrates and remove water from the powder causing a reduction in solid concentration percentage while increasing the porosity of the surface [16]. This is the result of water leaving the spaces in the powder. Powder A is the most porous out of all the powders as seen in the images above. In theory, the higher porosity of powder the larger the surface area exposed for coagulation to remove dye. Based on that theory, powder A should have the best coagulation performance compared to the other powder samples. Therefore, the best powder based on surface morphology is powder A. 


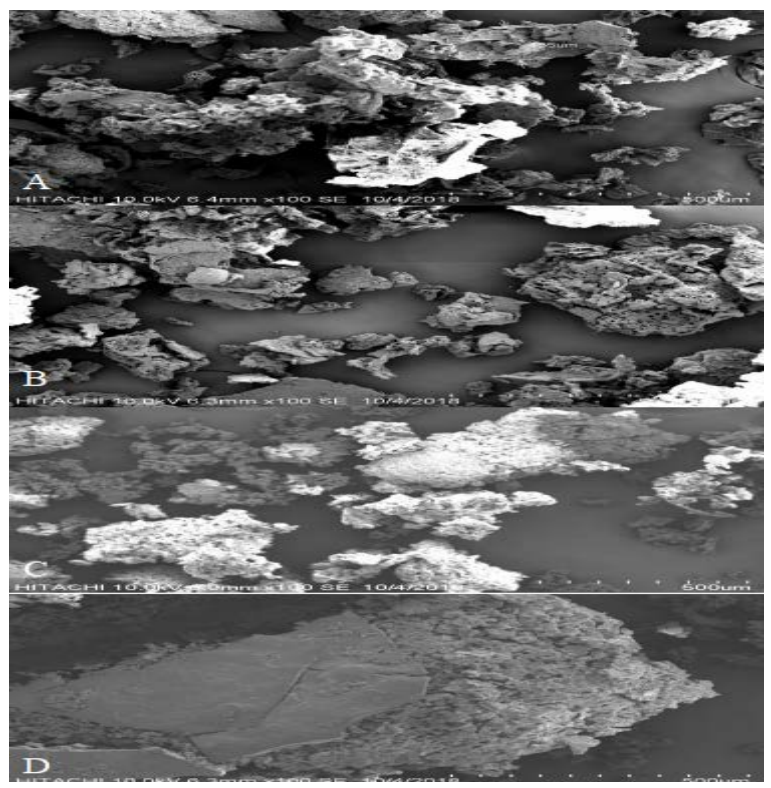

Fig.3. Powder surface morphology (A: $20 w t \%, 24$ hours; B: $30 w t \%, 24$ hours; C: $20 w t \%, 65$ hours; D: $30 w t \%, 65$ hours)

\subsection{Water solubility}

1 gram of Hibiscus Sabdariffa powder with $100 \mathrm{ml}$ of distilled water mixture is blended in a blender. Blended solution was transferred into $50 \mathrm{ml}$ centrifuge tubes. The samples are centrifuged at $3000 \mathrm{rpm}$ for 5 minutes. Samples from the centrifuge tubes is transfer into petri dishes. The petri dishes are dried in an oven at temperature of $105^{\circ} \mathrm{C}$ for a total of 5 hours. Petri dish will then be weight using electronic weight balance to obtain the weight of the residue that is left on the petri dish. Solubility of the Hibiscus Sabdariffa powder can then be obtained using the Equation (1).

$$
\text { Solubility }(\%)=\frac{\text { Weight of residue on petri dish }}{\text { Initial weight of sample }} \times 100 \%
$$

Based on Table 1, powder A of concentration $20 w t \%$ and freeze-drying duration of 24 hours shows the higher solubility percentage. This means that powder A is the most porous out of all the other powders further confirming the validity of claim made on figure 3 where powder A is the most porous. As in theory, increase in surface porosity leads to higher water solubility of powder [16]. Based on theory discussed in surface morphology testing, the higher water solubility the higher the coagulation performance of the powder. Therefore, based on the results so far, powder $\mathrm{A}$ is the best option at removing dye from dye wastewater.

Table 1: Water solubility of each powder

\begin{tabular}{|c|c|c|c|}
\hline Powder & Concentration $(\boldsymbol{w t} \%)$ & Freeze drying duration (hr) & Solubility (\%) \\
\hline A & 20 & 24 & 57 \\
B & 30 & 24 & 44 \\
\hline C & 20 & 65 & 40 \\
\hline D & 30 & 65 & 47.2 \\
\hline
\end{tabular}




\subsection{Water activity}

Water activity meter called AquaLab Lite is a meter that utilizes a dielectric humidity sensor to measure the water activity. This meter is used due to its accuracy [17]. Water activity is the measure of how much water is present in the sample denoted as $\mathrm{a}_{\mathrm{w}}$. Sample is placed into the AquaLab Lite meter to measure the water activity of the samples. Table 2 below, shows the water activity obtained for the samples of different concentrations and freeze-drying durations.

Water activity shows the amount of water content in the Hibiscus Sabdariffa powder. The lower the water activity the better as lower water activity prevents the growth of microorganisms that decomposes the protein content in the powder. Water activity should be below 0.6 to reduce the likelihood of microorganism growth [18]. While all the powders have water activity below 0.6 . The powders A and B prepared with freeze drying duration of 24 hours show better results as in the water activity is the lower compared to powders $C$ and D prepared from freeze drying duration of 65 hours. In theory longer freeze-drying duration should have lower water activity, but the opposite is true where freeze drying duration of 65 hours have higher water activity. This may have been due to the moisture that the powder absorbs over that extended time frame. However, based on Table 2 above powder A has the second lowest water activity which would mean powder B is the better alternative. When taking the porosity seen in image found in figure 3 and the solubility value found in Table 1 above. Powder A is still the best option as it has the highest porosity, highest water solubility and second lowest water activity. As mentioned before, higher porosity and water solubility of powder allows more surface area for coagulation with dye directly leading to higher coagulation performance of Hibiscus Sabdariffa powder. This means that powder A should have the highest coagulation performance based on theory. Since powder A is chosen the low water activity of powder A allows it to have protein retention properties at water activity of 0.478 is below 0.6 where the chances of microorganism growing and degrading the protein is halted. Fourier Trasnform Infrared spectroscopy testing below should be a prove of the claims made here where protein retention properties of Hibiscus Sabdariffa powder is due to freeze drying.

Table 2: Water activity of each powder

\begin{tabular}{|c|c|c|c|}
\hline Powder & Concentration $(\boldsymbol{w t} \%)$ & Freeze drying duration $(\mathbf{h r})$ & Water activity $\left(\mathbf{a}_{\mathbf{w}}\right)$ \\
\hline A & 20 & 24 & 0.478 \\
\hline B & 30 & 24 & 0.458 \\
\hline C & 20 & 65 & 0.565 \\
\hline D & 30 & 65 & 0.538 \\
\hline
\end{tabular}

\subsection{Fourier transform infrared spectroscopy}

A spectrometer is used to carry out Fourier Transform Infrared spectroscopy a method used to identify the presence of protein in the Hibiscus Sabdariffa seed and powder [19]. This is done by identification of amino acids which is a functional group of protein in the seed and powder sample. Figures 4 and 5 are results obtained from Fourier Transform Infrared spectroscopy on Hibiscus Sabdariffa seed and powder, respectively. This is to compare if the protein in the seed is preserved and retained after the seed is grinded into powder and undergone freeze-drying process.

Based on Figures 4 and 5, the band range is relatively wide at 4000 to $3000 \mathrm{~cm}^{-1}$. This wide band range is because of the presence of $\mathrm{O}-\mathrm{H}$ in both seed and powder samples. As a result, acid group consisting of carboxylic acid is present in both seed and powder samples. The steep curves in graph based on Figure 4 and 5 above from 3000 to $2000 \mathrm{~cm}^{-1}$ is indicates 
that both seed and powder samples are rich in fatty acids. In Figure 4 steep curves starting from $1634 \mathrm{~cm}^{-1}$ and steep curves starting from $1628 \mathrm{~cm}^{-1}$ indicates that both seed and powder samples have protein amide. Therefore, based on the Fourier Transform Infrared spectroscopy results protein can be said to be preserved and retained in the powder. This is because carboxylic acid can be found in the powder indicating the presence of proteins responsible for the coagulation action which are aspartic acid and glutamic acid. Therefore, it is proven that freeze drying does allow Hibiscus Sabdariffa powder to have protein retention properties proving the validity of water activity test results. Therefore, it is proven that freeze drying does help increase the shelf-life of Hibiscus Sabdariffa as a natural coagulant due to protein retention properties. Furthermore, in theory, freeze drying should also maintain the coagulation performance of Hibiscus Sabdariffa powder better than direct method can. Tests of effects of coagulant dosage on dye removal percentage and effects of $\mathrm{pH}$ value of preparation methods on colour removal percentage below should prove that coagulation performance of Hibiscus Sabdariffa powder prepared from freeze drying should be better compared to direct method.

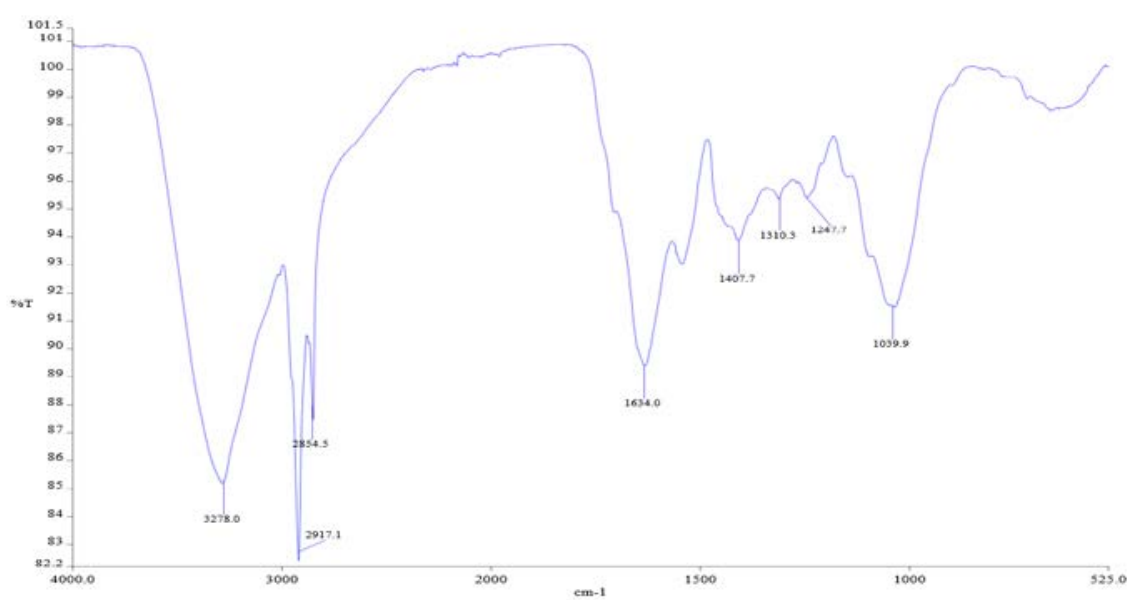

Fig. 4. Fourier Transform Infrared result based on Hibiscus Sabdariffa seed

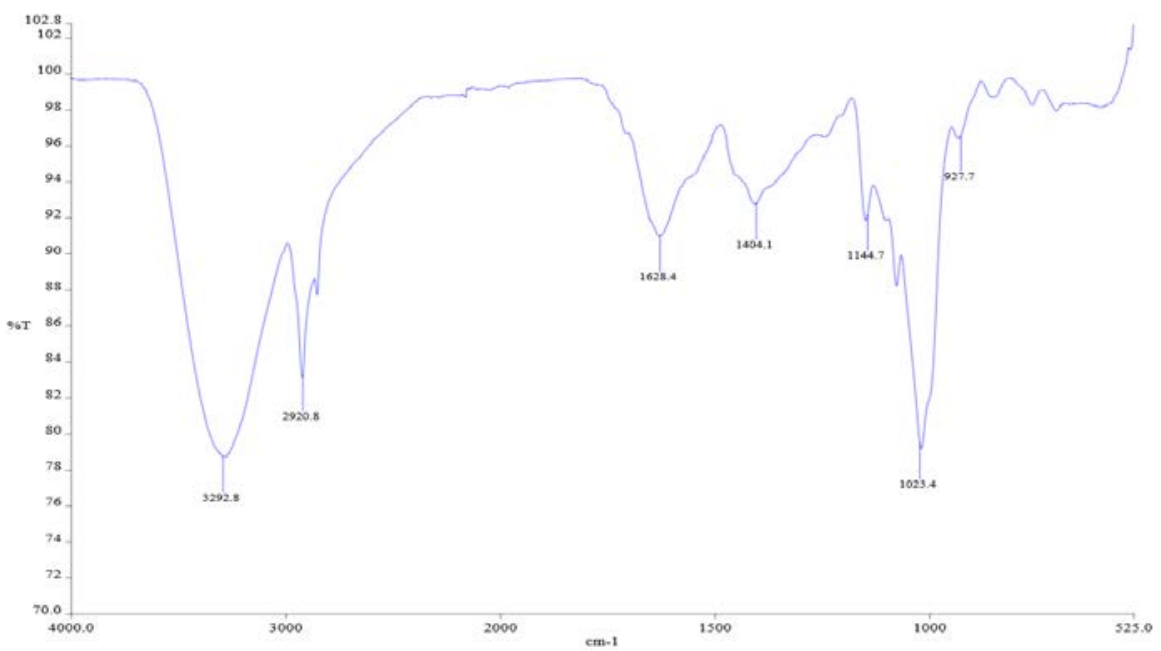

Fig. 5. Fourier Transform Infrared result based on Hibiscus Sabdariffa powder 


\subsection{Effects of coagulant dosage on dye removal percentage}

Jar test is conducted to determine the coagulation performance difference by measuring the color removal percentage between direct method and Hibiscus Sabdariffa prepared by freeze drying at different coagulant dosages. Jar test conducted for direct and freeze-drying method for testing of dye removal percentages at different coagulant dosages. Dosages for direct method is from 500 to $3500 \mathrm{mg} / \mathrm{L}$ while dosage for freeze-drying is from $300-1800$ $\mathrm{mg} / \mathrm{L}$ as in theory freeze-drying should have better coagulation and dye removal performance which is why freeze-drying would require less dosage to remove the same amount of dye. The varied coagulant dosages are determined based on trial-and-error method. Dye removal percentage as seen in Figure 6. It shows in dip in dye removal percentage indicating that coagulant dosage of direct method is above the optimum dosage required at $3000 \mathrm{mg} / \mathrm{L}$ [20].

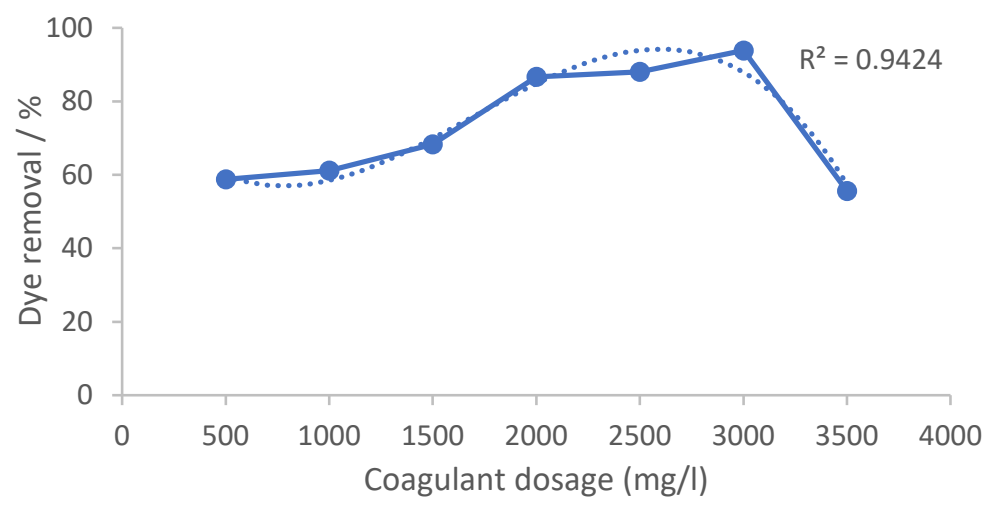

Fig. 6. Direct method dye removal percentage at varied coagulant dosages

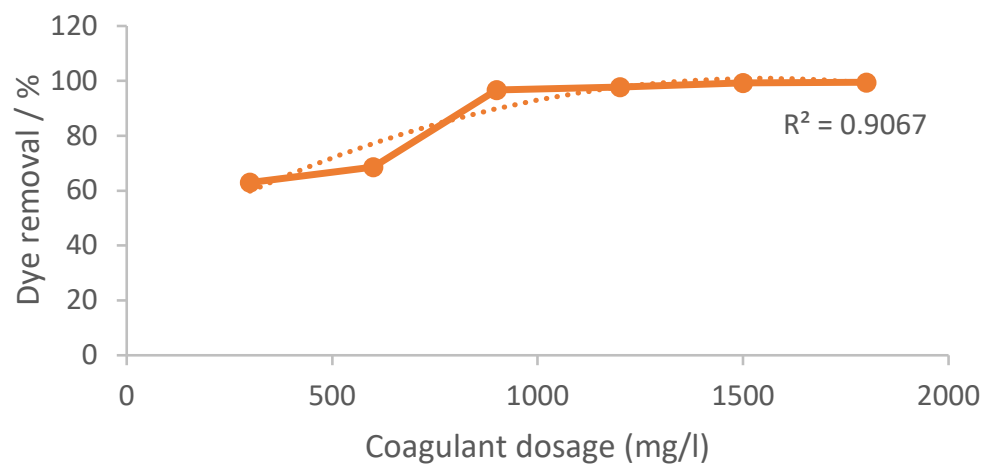

Fig. 7. Freeze-drying method dye removal percentage at varied coagulant dosages

Based on Figures 7 and 6, the optimum dosage of coagulant for maximum dye removal percentage achieved by powder (freeze drying) is at $1800 \mathrm{mg} / \mathrm{L}$ of coagulant while the seed (direct method) reaches maximum dye removal percentage at $3000 \mathrm{mg} / \mathrm{L}$. Furthermore, powder coagulant reaches a dye removal percentage close to $100 \%$ while the seed is only at around $96 \%$ of dye removal. Therefore, it can be said that powder coagulant is better compared to seed coagulant as it requires far less coagulant dosage at a difference of $1200 \mathrm{mg} / \mathrm{L}$ while boasting a higher dye removal percentage at close to $100 \%$ compared to 
$96 \%$. This means that powder coagulant prepared from freeze drying would be better in terms of coagulation performance and at the same time cheaper as fewer coagulant dosages are required [21]. Since dye removal percentage of freeze drying has reached a plateau between coagulant dosage of $1500 \mathrm{mg} / \mathrm{L}$ to $1800 \mathrm{mg} / \mathrm{L}$ based on Figure 7 . It is better to choose $1500 \mathrm{mg} / \mathrm{L}$ as the optimum powder coagulant dosage to reduce the usage and cost of coagulant. This further supports the fact that natural coagulant powder prepared from freeze drying requires less coagulant dosage compared to direct method. Therefore, it can be concluded that Hibiscus Sabdariffa powder prepared from freeze drying is better compared to direct method based on coagulation performance and the dosage required.

\subsection{Effects of $\mathrm{pH}$ value of preparation methods on colour removal percentage}

Figure 8 shows a jar test is conducted to determine the coagulation performance difference by measuring the colour removal percentage between direct method and Hibiscus Sabdariffa prepared by freeze drying at different $\mathrm{pH}$ values of 2, 7 and 12 . Even at varied $\mathrm{pH}$ values of 2,7 and 12 the colour removal percentage is always higher with the freeze-drying method compared to the direct method. This further validates the claims made where freeze drying method of preparing natural coagulant Hibiscus Sabdariffa has better coagulation performance compared to direct method. The Hibiscus Sabdariffa powder prepared from freeze-drying can then be compared to chemical coagulant alum in terms of coagulation performance with jar test as the freeze drying is proven to the be the better option compared to direct method in terms of coagulation performance.

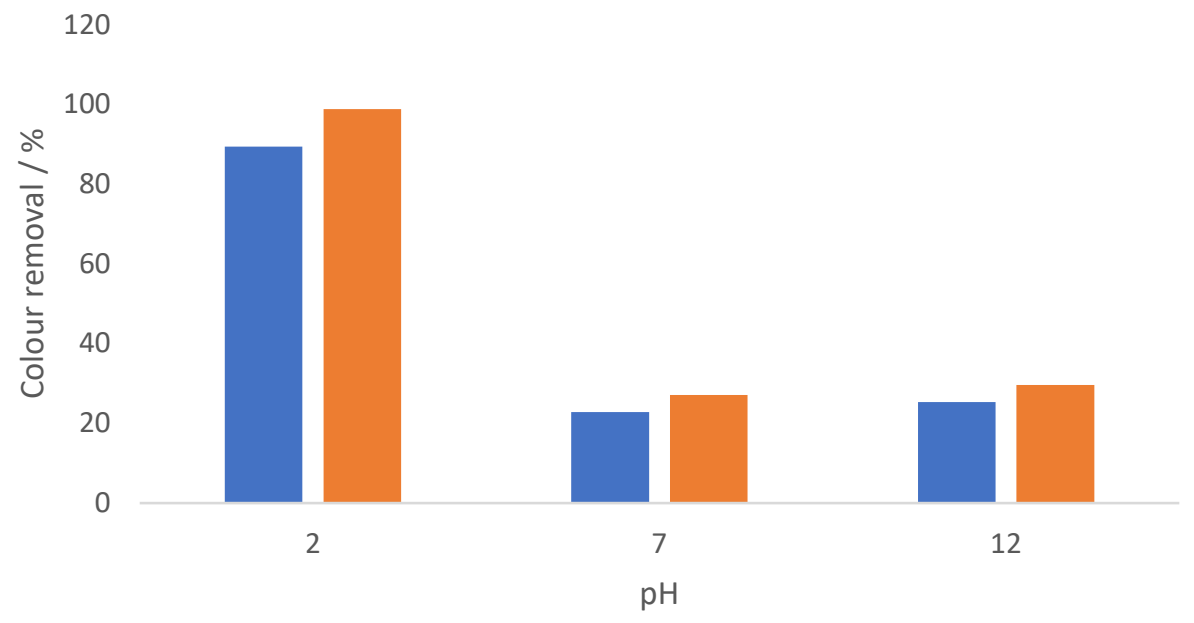

Direct method $\quad$ Hibiscus sabdariffa powder by freeze drying

Fig. 8. Color removal percentage at varied $\mathrm{pH}$ value of freeze-drying and direct method

\subsection{Jar test for colour removal comparison between natural and chemical coagulant}

Jar test is to compare the performance of Hibiscus Sabdariffa as a natural coagulant to remove dye which is measured in colour removal compared to chemical coagulant alum [22]. This is where initial concentration of colour in the dye wastewater is $400 \mathrm{ppm}$ with dosage of $190 \mathrm{mg} / \mathrm{L}$ of Hibiscus Sabdariffa powder. The optimum $\mathrm{pH}$ for this test is $\mathrm{pH}$ value of 2 . 
As a result, jar test using chemical coagulant where alum is used follows the same initial concentration of colour for dye wastewater, dosage as well as $\mathrm{pH}$ value. This is for the sake of fair comparison. The coagulation performance of natural coagulant and chemical coagulant should be comparable. Although, natural coagulant will have slightly lower coagulation performance, the other benefits such as being safer for the environment and nontoxic to living organisms is beneficial. Colour removal test is basically a general test where colour is removed via coagulation. Colour removal test on comparing Hibiscus Sabdariffa powder and alum is as shown Figure 9 [22].

Based on Figure 9, colour removal percentage of Hibiscus Sabdariffa at 91.2\% compared to alum at $92.3 \%$. This shows that natural coagulant Hibiscus Sabdariffa prepared from freeze drying method has comparable coagulation performance compared to synthetic coagulant alum. This means that in terms of coagulation performance at removing colour or dye especially, natural coagulant Hibiscus Sabdariffa prepared from freeze drying method is a possible alternative to replace synthetic coagulant alum in the water treatment industry. This coagulation performance of Hibiscus Sabdariffa as a natural coagulant is only achieved by application of freeze drying. This is where improvements in surface morphology, water solubility and decrease in water activity and protein retention properties in Hibiscus Sabdariffa powder is obtained.

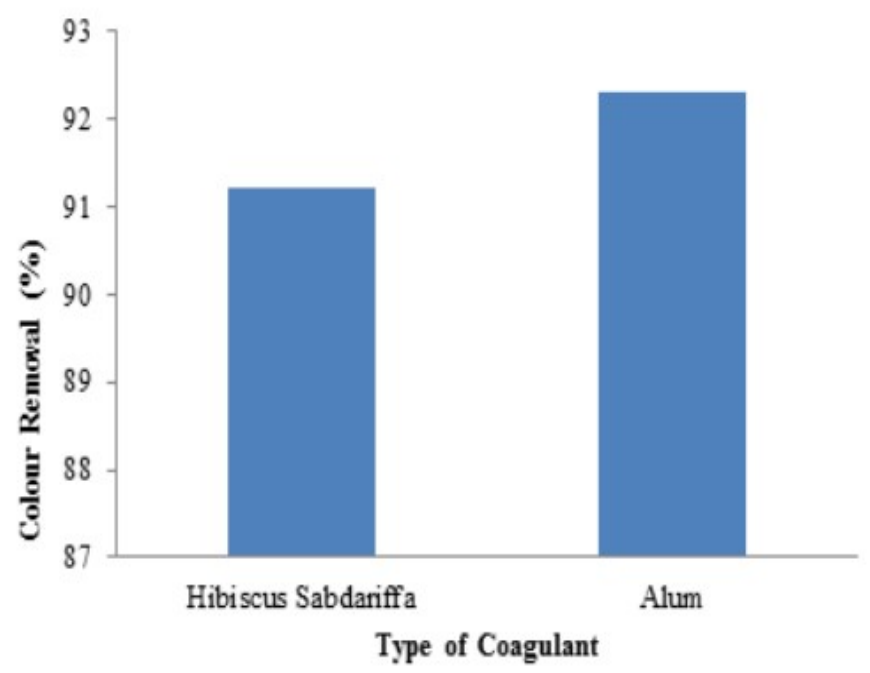

Fig. 9. Colour removal test on Hibiscus Sabdariffa powder and alum [22]

Table 3 shows the inventory analysis on the economic and environmental aspects that chemical alum and natural coagulant Hibiscus Sabdariffa has along with its impact categories. The water treatment process (coagulation) to treat dye helps reduce the water pollution caused by dye wastewater. It reduces the impact category of freshwater aquatic ecotoxicity. This treatment of dye reduces the impact of dye on the colour of water that dampens the rate of photosynthesis of aquatic plants. Thus, reducing the damage dye causes to aquatic plants and the disruption on the food chain/food web. Aquatic life is less negatively affected as their source of food which is aquatic plants is less negatively affected by dye wastewater. More importantly, coagulation helps remove dye and can be said to reduce the effect that dye has on impact category of freshwater aquatic ecotoxicity due to reduction of damage to aquatic life and plants. Impact category of water pollution and hazardous waste disposal is also reduced as dye a hazardous waste is removed from the water by treating it 
using coagulation. Chemical sludge formed from use of chemical coagulant disposed is nonbiodegradable. Chemical sludge disposal is considered a hazardous waste to dispose. It contributes of impact category of water pollution, freshwater aquatic ecotoxicity and human toxicity as it is detrimental to aquatic life as well as human beings because chemical coagulants present is sludge are metals such as aluminium and iron. These metals are considered toxic if consumed as it is known to impair organ function as well as other biological functions [23]. An article even suggests the chemical coagulants do contribute to neurological diseases such as Alzheimer's [3].

Natural coagulants produce biodegradable sludge. Biodegradable sludge is a nonhazardous waste to dispose to the environment. Biodegradable sludge makes natural coagulant a more environmentally friendly alternative as it can be broken down by bacteria and fungus to produce biomass, water and carbon dioxide which are safer by products compared to heavy metals from sludge produced by use of chemical coagulant [24]. It is also not toxic as natural coagulant is made up of protein which makes it safer to aquatic life as well as human beings [3].

Chemical coagulant alum contributes to water pollution with waste such as sulphuric acid $\left(\mathrm{H}_{2} \mathrm{SO} 4\right)$, aluminium hydroxide $\left(\mathrm{Al}(\mathrm{OH})_{3}\right)$, and municipal solid waste (MSW). The threewaste mentioned also contributes to aquatic ecotoxicity. With sulphuric acid being corrosive and toxic which is bad for aquatic life as it can damage the cells of aquatic life. Aluminium hydroxide on the other hand is contributes to water pollution as aluminium ions dumped into the river and can even leach from soil into the river. Aluminium hydroxide is a form of toxic heavy metal which can affect the bodily functions of aquatic life due to heavy metal accumulation [23]. Municipal solid waste (MSW) is produced from usage of electricity contributes to aquatic ecotoxicity, human toxicity and terrestrial ecotoxicity and all of which is due to water pollution. This is because MSW consist of plastic and metal waste. Ingestion of plastic waste by aquatic life can lead to health complications and even death. Heavy metal waste negatively affects all live forms from human, animals, and aquatic life as these metals can accumulate in the body affecting normal bodily function. Health complications are very possible from ingestion of these heavy metals as it can cause damage and function of organs such as brain, liver, and kidney [25].

All the gas emissions from production of chemical coagulant leads to air pollution. $\mathrm{SO}_{2}$, $\mathrm{SO}_{3}$, and $\mathrm{NO}$ gas emissions also contribute to acid rain formation where impact category is under acidification [26]. Acid rain is known to kill aquatic life as they raise the $\mathrm{pH}$ value of the environment that they live in [27]. Furthermore, acid rain is also causing respiratory issues in humans and animals as these gasses can cause asthma [27]. Gas emissions $\mathrm{SO}_{2}, \mathrm{CO}$, and NO indirectly contribute to global warming as these gasses are considered indirect greenhouse gasses [28]. Direct greenhouse gasses are $\mathrm{CO}_{2}, \mathrm{~N}_{2} \mathrm{O}$ and $\mathrm{CH}_{4}$ [26]. Regardless, $\mathrm{SO}_{2}, \mathrm{CO}$, and $\mathrm{NO}$ gasses contribute to greenhouse effect as these gasses reflect the sunrays back to Earth causing the Earth to heat up and increase in temperature also known as global warming. Global warming is a very serious issue as it contributes to destruction of habitat such as melting of ice glaciers where polar bears lose their habitat. This possibly contributes to killing the animals and aquatic life that live there. It also contributes to a rise in sea level which will cause the flooding and even completely submerge countries in the future which is an issue in terms of social aspect as well as the environment. This is because complete submersion of land is uninhabitable by humans as well as land animals [29]. CO gas is classified under human toxicity as it is known to cause oxygen deprivation in humans by replacing oxygen in the blood possibly causing suffocation [30]. NO gas is also known to cause respiratory tract damage which is classified under human toxicity and negatively affect crop yield affecting the food production industry. This would cause starvation and even the death of humans and animals in poorer or less developed countries that lacks the resources, technology, and knowledge to handle these crop yield issue [30]. 
Table 3: Inventory Analysis on Chemical Coagulant and Natural Coagulant [26]

\begin{tabular}{|c|c|c|c|c|}
\hline Aspects & $\begin{array}{c}\text { Synthetic/Chemical } \\
\text { Coagulant }\end{array}$ & Impact Category & Natural Coagulant & Impact Category \\
\hline $\begin{array}{c}\text { Economic } \\
\text { (Cost) }\end{array}$ & RM 222933.76/year & - & RM1729161.97/year & - \\
\hline \multirow{9}{*}{ 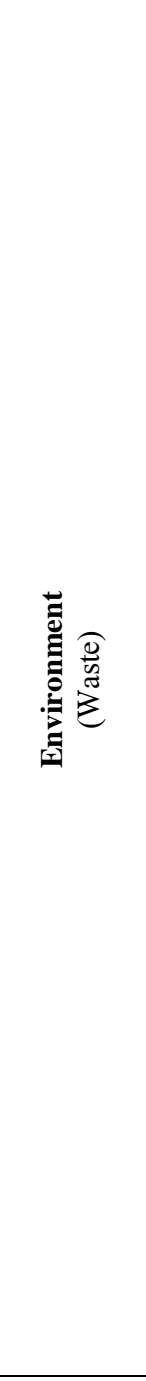 } & $\begin{array}{l}\text { Annual Dry Sludge } \\
\text { Production } \\
=547500 \mathrm{~kg} \text { dry } \\
\text { sludge/year }\end{array}$ & $\begin{array}{c}\text { Aquatic Eco- } \\
\text { toxicity \& Human } \\
\text { toxicity } \\
\text { (Water Pollution) }\end{array}$ & $\begin{array}{l}\text { Annual Dry Sludge } \\
\text { Production } \\
=547500 \mathrm{~kg} \text { dry } \\
\text { sludge } / \text { year }\end{array}$ & Non-Toxic \\
\hline & $\begin{array}{c}\text { Annual Sulphuric Acid } \\
\text { Waste } \\
=2426.88 \mathrm{~kg} / \text { year }\end{array}$ & $\begin{array}{l}\text { Aquatic Eco- } \\
\text { toxicity (Water } \\
\text { Pollution) }\end{array}$ & $\begin{array}{l}\text { Annual Fertilizer Waste } \\
=158886 \mathrm{~kg} / \text { year }\end{array}$ & Eutrophication \\
\hline & $\begin{array}{l}\text { Annual Aluminium } \\
\text { Hydroxide Waste } \\
=2897.08 \mathrm{~kg} / \text { year }\end{array}$ & $\begin{array}{l}\text { Aquatic Eco- } \\
\text { toxicity (Water } \\
\text { Pollution) }\end{array}$ & $\begin{array}{c}\text { Annual Pesticide Waste } \\
=203.32 \mathrm{~L} / \text { year }\end{array}$ & $\begin{array}{l}\text { Aquatic Eco- } \\
\text { toxicity (Water } \\
\text { Pollution) }\end{array}$ \\
\hline & $\begin{array}{c}\text { Annual Municipal Solid } \\
\text { Waste } \\
=71351.24 \mathrm{~kg}\end{array}$ & $\begin{array}{c}\text { Aquatic Eco- } \\
\text { toxicity, } \\
\text { Human Toxicity } \\
\text { \&Terrestrial Eco- } \\
\text { toxicity } \\
\text { (Soil \& Water } \\
\text { Pollution) }\end{array}$ & & \\
\hline & $\begin{array}{c}\text { Annual Wastewater } \\
=28.82 \mathrm{~m}^{3} / \text { year }\end{array}$ & Water Pollution & & \\
\hline & $\begin{array}{l}\text { Annual } \mathrm{SO}_{2} \text { Emission } \\
=1.446 \times 10^{9} \mathrm{~kg} / \text { year }\end{array}$ & $\begin{array}{c}\text { Acidification \& } \\
\text { Global Warming } \\
\text { (Indirect } \\
\text { Greenhouse Gas) } \\
\end{array}$ & & \\
\hline & $\begin{array}{c}\text { Annual } \mathrm{SO}_{3} \text { Emission } \\
\text { Annual } \\
=1.014 \times 10^{7} \mathrm{~kg} / \text { year } \\
\end{array}$ & Acidification & & \\
\hline & $\begin{array}{c}\text { CO Emission } \\
=1.229 \times 10^{10} \mathrm{~kg} / \text { year }\end{array}$ & $\begin{array}{l}\text { Global Warming \& } \\
\text { Human Toxicity } \\
\text { (Indirect } \\
\text { Greenhouse Gas) }\end{array}$ & & \\
\hline & $\begin{array}{l}\text { Annual NO Emission } \\
=5.18 \times 10^{7} \mathrm{~kg} / \text { year }\end{array}$ & $\begin{array}{c}\text { Eutrophication, } \\
\text { Acidification, } \\
\text { Global Warming \& } \\
\text { Human Toxicity } \\
\text { (Indirect } \\
\text { Greenhouse Gas) } \\
\end{array}$ & & \\
\hline
\end{tabular}

Waste is still produced from use and production of natural coagulant and should not be taken lightly as fertilizer waste produced contributes to eutrophication. This is where nutrients from the use of fertilizer leeches to a nearby river. Eutrophication leads to algae bloom which floats on top of the river [31]. This blocks sunlight from reaching aquatic plants causing a reduction in aquatic plant and as a result food sources for aquatic life will also reduce. To add on to that, the algae also compete for nutrient and oxygen reducing the essential basic needs for aquatic plant and life to survive. Thus, the entire ecosystem in the river is disrupted leading to the possible death of all aquatic plant and life in the river. NO gas emission from use of synthetic coagulant also contributes to eutrophication but since it is in terms of gas emission, the effect is less severe compared to eutrophication caused by natural coagulant [26]. However, natural coagulant is the more sustainable and better option 
compared to chemical coagulants based on environmental and social factors observed in Life Cycle Analysis study. This is because based on all the waste produced from chemical coagulant alum, the effects are not only averse to the environment but also the health of living beings. To add on to that, the annual waste production from production of chemical coagulant alum is also in relatively large quantities especially the gas emissions. Compared to chemical coagulant, waste produced from use and production of natural coagulant is far lower in quantity. Thus, natural coagulant Hibiscus Sabdariffa can be better for the environment and well-being and health of the society compared to synthetic coagulant alum.

\section{FINDINGS, CONCLUSION AND FUTURE WORK}

Based on experimental results obtained, freeze-drying of Hibiscus Sabdariffa powder is better compared to direct method of preparing the powder as natural coagulant. This is supported by surface morphology, water activity, and solubility results. Surface morphology experiment where powder A with concentration of $20 w t \%$ and 24 hours of freeze drying is found to be the most porous in terms of surface structure. As a result of this porosity, powder A has the best water solubility. As for water activity powder A has the second lowest water activity at $\mathrm{a}_{\mathrm{w}}=0.478$ which is below 0.6 . Water activity must be below 0.6 to ensure that there is not enough moisture in the powder to promote growth of microorganisms that decomposes and reduces the protein content in the powder affecting the coagulation performance of natural coagulant as protein is responsible for coagulation process. The Hibiscus Sabdariffa powder prepared from freeze drying also shows protein retention properties based on Fourier Trasnform Infrared spectroscopy test. Dye and colour removal percentage of Hibiscus Sabdariffa prepared from freeze drying is always higher compared to direct method even at varied $\mathrm{pH}$ of 2,7 and 12. Coagulation performance of Hibiscus Sabdariffa prepared from freeze drying is also better compared to direct method while needing lower coagulant dosages. Thus, with all the supporting data on powder A prepared from freeze drying is the better option compared to direct method of preparing Hibiscus Sabdariffa powder as a natural coagulant.

Coagulation performance of natural coagulant Hibiscus Sabdariffa prepared from freeze drying is comparable to that of synthetic coagulant alum. Thus, based on coagulation performance natural coagulant Hibiscus Sabdariffa can be considered an alternative to synthetic coagulant alum in terms of coagulation performance. Based on Life Cycle Analysis conducted comparing natural coagulant Hibiscus Sabdariffa prepared with freeze drying method is compared to chemical coagulant alum. Comparison is done based on the 3 sustainability aspects which are economic, environment and social aspects. Natural coagulant is found to be more sustainable and the better option compared to chemical coagulants in terms of impact to environmental and well-being and health of society. This is because the amount of waste produced from production and use of natural coagulant is far lesser compared to waste produced from production and use of chemical coagulant alum. This would mean that the negative effects of production and usage of natural coagulant is less severe compared to production and use of chemical coagulant. However, natural coagulant Hibiscus Sabdariffa also has the drawback where growth and production of the natural coagulant is affected by uncertainties such as weather changes, drought, and sun light exposure. This makes Hibiscus Sabdariffa production as a natural coagulant less consistent compared to chemical coagulant that can be produced in a continuous manner. Natural coagulant also takes a long time to grow and mature to produce the seeds needed for coagulation to treat wastewater. Although, these drawbacks are reduced with incorporation of freeze-drying method to prepare Hibiscus Sabdariffa powder as a natural coagulant.

This is where freeze-drying helps preserve the protein content in the Hibiscus Sabdariffa powder responsible for coagulation. Meaning that the protein content and coagulation 
performance of the powder does not degrade even when the powder is stocked piled. It allows the powder to be prepared beforehand to smoothen the consistency of powder production to help satisfy the coagulant requirement to treat wastewater. As a result, the commerciality of the Hibiscus Sabdariffa powder has be improved on. However, based on an economic standpoint natural coagulant is 126.86 times more expensive compared to chemical coagulant when production cost is considered. This may explain why natural coagulant has not replaced chemical coagulant in the wastewater treatment industry as money is what sustains the implementation of chemical coagulant but not the natural coagulant. However, natural coagulant Hibiscus Sabdariffa has its environment and social benefits compared to chemical coagulant alum. Furthermore, the natural coagulant has comparable coagulation performance in removing dye when compared to chemical coagulant alum. This means that natural coagulant is a possible alternative that may replace chemical coagulant in the future. Given that the cost of production for natural coagulant is reduced. As for future research, the parameters for experimentation on performance of natural coagulant can be broaden with experiments to test BOD and COD removal. Different and better extraction methods of producing the natural coagulant can also be researched upon. Shelf life of the natural coagulant should also be determined and improved on to improve the commerciality of the natural coagulant.

\section{REFERENCES}

[1] M. Kostoglou, M.C. Georgiadis, Comput. Aided Chem. Eng. 29, 41 (2011)

[2] E. Łukasiewicz, Econ. Environ. Stud. 16, 831 (2016)

[3] S.N. Ugwu, A.F. Umuokoro, E.A. Echiegu, B.O. Ugwuishiwu, C.C. Enweremadu, Cogent. Eng. 4, 1365676 (2017).

[4] F. Tounkara, T. Amza, C. Lagnika, G.W. Le, Y.H. Shi, Songklanakarin J. Sci. Technol. 35, 159 (2013)

[5] A. Ciurzyńska, A. Lenart, Polish. J. Food Nutr. Sci. 61, 165 (2011)

[6] A. L. Goldberg, Protein Degradation, in Encyclopedia of Biological Chemistry: Second Edition, (Elsevier, Amsterdam, 2013)

[7] "Hibiscus Propagation: How To Propagate Hibiscus", H. Rhoades, 2020. [Online]. Available:https://www.gardeningknowhow.com/ornamental/flowers/hibiscus/hibiscus propagation.htm\#: :text=Water $\% 20$ the $\% 20$ soil $\% 20$ once $\% 20$ the,take $\% 20$ up $\% 20$ to $\% 2$ 0four\%20weeks

[8] D. Caro, Carbon footprint, in Encyclopedia of Ecology: Second Edition (Elsevier, Amsterdam, 2018)

[9] “Town", Wikipedia, 1996. [Online]. Available : https://en.wikipedia.org/wiki/Town\#: :text=Typically\%2C\%20once\%20a\%20town\% 20reaches,township \%22\%20or\%20\%22village.\%22

[10] "Changing Consumer Attitudes Towards Water", K. Kamarudin, 2020. [Online]. Available:https://www.bernama.com/en/features/news.php?id=1816022\#: :text=Base d.

[11] "Calculation the Optimum Alum Dosages Used in Several Drinking", A. Jaeel, 2017. [Online]. Available :

https://www.researchgate.net/publication/322626519_Calculation_the_Optimum_Alu m_Dosages_Used_in_Several_Drinking

[12] G. Mannina, Frontiers in Wastewater Treatment and Modelling, (Springer Nature, Switzerland, 2017)

[13] P. Mishra, S. Mishra, C.L. Mahanta, Food Bioprod. Process. 92, 252 (2014).

[14] E.H. Mohamed, T.A. Mohammad, M.J.M.M. Noor, A.H. Ghazali, Water Treat. 5, 3628 (2015). 
[15] R.F. Batchelor, B.G. Lewis, A.D. Wilson, J. Dent. 9, 311 (1981).

[16] S. Rogers, W.D. Wu, J. Saunders, X.D. Chen, Dry. Technol. 26, 404 (2008)

[17] "AquaLab LITE Manual, Decagon Devices", Issue, 2008. [Online]. Available: https://issuu.com/decaweb/docs/aqualablite

[18] J. Langová, D. Jaisut, R. Thuwapanichayanan, C. Phowong, J. Stencl, D. Jovanovic, J. Fryc, V. Vlasek. Acta Univ. Agric. Silvic. Mendelianae Brun. LXI. 196 (2013).

[19] A. Barth, Biochim Biophys Act. 1767, 1073 (2007).

[20] J. C. Crittenden, R. R. Trussell, Hand, D. W. Hand, K. J. Howe, G. Tchobanoglous, MWH Water Treatment: Principles and Design, 3rd edition, (John Wiley \& Sons, New Jersey, 2012)

[21] "Effect of Mixing Natural Coagulant with Alum on Water Treatment", G. Hayder, A. A. Rahim, 2015. [Online]. Available: http://dspace.uniten.edu.my/jspui/handle/123456789/10229

[22] M. Y. Yong, N. Ismail, J. Eng. Sci. Technol. 11, 153 (2016).

[23] S. P. Singh, S. Kaur, D. Singh, Food toxicology-past, present, and the future (The Indian perspective), in Food Safety in the 21st Century: Public Health Perspective, (Elsevier, Amsterdam, 2016).

[24] A. S. Luyt, S. S. Malik, Can biodegradable plastics solve plastic solid waste accumulation?, in Plastics to Energy: Fuel, Chemicals, and Sustainability Implications, (Elsevier, Amsterdam, 2018).

[25] S. E. Vergara, G. Tchobanoglous, Annu Rev Environ Resour. 37, 277 (2012).

[26] E. Nieuwlaar, Life Cycle Assessment and Energy Systems, in Reference Module in Earth Systems and Environmental Sciences, (Elsevier, Amsterdam,2013).

[27] "Effects of Acid Rain, United States Environmental Protection Agency", EPA, 2020. [Online]. Available: https://www.epa.gov/acidrain/effects-acid-rain\#: :text=

[28] "Chemical Relationships between Greenhouse Gases and Air Pollutants in Biomass Energy Production", H. Satein, 2009. [Online] Available :

https://www.beyondtoxics.org/wp-content/uploads/2011/11/OTA_ReportBiomassContributors_to_ClimateChange7-28-09.pdf

[29] "Sea level rise, explained", C. Nunez, 2019. [Online]. Available : https://www.nationalgeographic.com/environment/global-warming/sea-level-rise/

[30] T. Gordon, L. W. Stanek, J. Brown, Pollution, Air in Encyclopedia of Toxicology, Third Edition, (Elsevier, Amsterdam, 2014).

[31] J. Frederick Grassle, Marine Ecosystems, in Encyclopedia of Biodiversity: Second Edition, (Elsevier, Amsterdam, 2014). 